\title{
National Association of Directions of Educational Research
}

\section{E. J. Ashbaugh}

To cite this article: E. J. Ashbaugh (1922) National Association of Directions of Educational Research, The Journal of Educational Research, 5:1, 93-96, DOI: 10.1080/00220671.1922.10879235

To link to this article: http://dx.doi.org/10.1080/00220671.1922.10879235

曲 Published online: 15 Dec 2014.

Submit your article to this journal $\sqsubset$

Q View related articles ๘ 
Chicago and Terman tests, with a correlation of 0.68 , agree on the placement of 10 percent more pupils than do the Otis and Chicago tests with a correlation of 0.78. In no case is percent agreement in placement as high as the correlation might suggest without such a comparison as this. The above discussion appears to the writer as an additional warning against loose interpretations of coefficients of correlation.

Table IV-Correlations and Per Cent Agreement in Classification

\begin{tabular}{l|c|c|c}
\hline \hline & \multicolumn{3}{|c}{ TESTS } \\
\cline { 2 - 4 } & Otis $\times$ Chicago & Otis $\times$ Terman & Chicago $\times$ Terman \\
\cline { 2 - 4 } $\begin{array}{l}\text { Correlations }{ }^{\mathrm{A}} \ldots \ldots . \\
\text { Percent agreement }\end{array}$ & $0.78 \pm 0.04$ & $0.72 \pm 0.05$ & $0.68 \pm 0.05$ \\
in Classification ... & 56 & 60 & 66 \\
\hline
\end{tabular}

a The coefficients of correlation were calculated by the product moment method from contingency tables.

As a final word on the classification as discussed above, it may be observed that according to the original data all three of the tests agree as to the classification of 22 of the 50 pupils, while at least two tests agree on 47 of them, the remaining three pupils being the only ones on which there is threefold disagreement. Thus where three such tests are available, a fairly satisfactory classification can be made.

KARL J. HOLZINGER

University of Chicago

\section{\$2ational Association of 呫irectors of (èucational Research}

(E. J. AshbaugH, Secretary and Editor)

Professor Fletcher Harper Swift of the College of Education, University of Minnesota, has lately been in Arkansas making a study of public school finance, as a part of the state survey of public education in Arkansas now being conducted under the direction of The Bureau of Education.

Chicago, Illinois.-Assistant Superintendent Wight, in charge of the Bureau of Educational Research has furnished us with a report of failures investigated in grades $6 \mathrm{~A}$ and $7 \mathrm{~B}$ of one school. The proportion of such failures in January, 1921, in 6A ranged from 14 percent in penmanship to 25 percent each in arithmetic, oral composition, and written composition. In 7B the percents ranged from 7 in spelling to 51 in arithmetic. An examination of intelligence by the use of the Illinois Examination indicated that the pupils 
were practically normal in mental ability. The achievement quotient or ratio between the accomplishment of these children and the normal accomplishment of children of like mentality showed that they were doing work in arithmetic much below their ability, while the work in reading was much above their mental status.

When achievement quotients are considered, it is quite apparent that the high percent of failure stated above cannot be justified on the basis of intelligence or the ability of pupils if it is granted that the test gives even a fair indication of what they can accomplish. We wonder how many pupils who fail and are compelled to repeat the work of the semester would also show normal mental ability or average grade achievement on the basis of standard tests.

Newark, New Jersey.-Elmer K. Sexton, Assistant Superintendent in charge of the Department of Reference and Research has just sent us a "Spelling Survey in the Public Schools of Newark." The testing was done in May, 1920. Twenty words were selected for each grade, the words being taken from the Ayres list, except in the seventh and eighth grades where the. Buckingham Extension and the Ashbaugh Scales furnished the remaining words. Sixty-six percent accuracy was the degree of difficulty of the words used. No word was selected for any grade unless, according to Jones' investigation, it was used by at least two percent of the pupils of the grade. The results of the survey, which involved nearly nine thousand children, show that the lower grades were below standard, while the upper grades were above. Grade three is more than a year below standard while $8 \mathrm{~A}$ is nearly a year above. It was felt that the large proportion of children from foreign speaking homes accounted for the poor work in the lower grades and it was gratifying to find that handicap overcome by the end of the school course.

One chart represents a comparison of the results in three groups of schools attended largely by pupils of American, Hebrew, and Italian parentage, respectively. The results in the Hebrew schools are best throughout the grades, maintaining uniform position above the Newark median. The American group begins in the third grade at the city average, rises above it in the $5 \mathrm{~A}$ grade and falls much below for the remainder of the grades, finishing the lowest of the three groups. The Italian group begins more than a year below standard in the third grade, makes rapid strides to the 5A, after which the improvement is less marked; but it finishes above the Ayres' standard and above the American group, although still much below the city median. We should be interested in knowing what other differences exist among the pupils of these three groups besides nationality.

Measurement of the intelligence of the $4 \mathrm{~B}$ and $8 \mathrm{~B}$ pupils in eight schools, four of the better and four of the poorer on the basis of surveys in arithmetic and spelling, showed that the intelligence score of the poorer group was below the intelligence score of the upper group, except in the case of one school. This one school, although low in intelligence, showed remarkable pedagogical results, due to splendid teaching, careful organization, and close supervision. 
The time devoted to spelling per week varied from 15 minutes to 150 minutes with mode and median at about 75 minutes. The number of words per lesson varied from two in $3 \mathrm{~A}$ and $5 \mathrm{~A}$ to fifty in $8 \mathrm{~A}$. There is no apparent difference in the time devoted to spelling in the better schools over the poorer schools; while the better schools appear to assign a slightly greater number of words per week. Many of the errors which were commonly found were easily traceable to poor pronunciation.

Wisconsin State Department.-W. J. Osburn, Director of Educational Measurements in the State Department of Public Instruction, has furnished us a twelve-page bulletin on "The Improvement of Ability in Reading." Attention has been called in these columns from time to time to the intensive work which this bureau has been doing in state supervision of reading during the last few years. The bulletin sets forth some general principles and emphasizes the thought that "rapid improvement" lies in the fact that we are learning what to practice, and when to practice it, and that we are discovering more and more how to make even the most formal work interesting to children.

The pupils who are deficient in silent reading ability fall naturally into four classes: (a) those who read carelessly and too rapidly; (b) slow reading; (c) lack of ability to analyze, organize, and supplement the thought contained in the material; (d) inability to remember what has been read, although it may have been well understood at the time. Suggestive exercises in reading material and type of check tests are given which should assist the teacher in remedying each of these difficulties when once recognized. The bulletin contains a type of material which will be greatly appreciated by those teachers and supervisors who have had enough scientific training to understand and value such work. A state department can probably render no greater service, especially to the school in the smaller community, than by furnishing detailed courses of study and specific helps such as are found in this bulletin.

Another report from the same department summarizes the errors in the Hotz Algebra test given in thirty-six schools in March and April, 1921. This summary of errors, together with the illustrative examples with specific wrong answers given, should be exceedingly helpful to the Algebra teachers of the state in focusing their attention upon the phases of Algebra which are likely to need emphasis.

This assumes, of course, that the types of examples and problems in this series of Algebra tests are the types of Algebraic work which it is the function of the schools to teach.

We are glad to announce the election of the following persons to membership in our association since the publication of the list in the May 1921 issue. Members who, from time to time issue material should add these names to their previous mailing list in order that all members of our association may receive the material.

Breed, F. S., University of Chicago, Chicago, $\mathrm{ml}$.

Clarke, J. R., Teachers College, Columbia University, New York City. 
Caldwell, O. W., Lincoln School, Teachers College, Columbia University, New York City.

Cubberley, E. P., Leland Stanford University, Stanford University, California.

Charters, W. W., Carnegie Tech., Pittsburgh, Pennsylvania.

Freeman, F. N., University of Chicago, Chicago, Ill.

Gates, Arthur I., Teachers College, Columbia University, New York.

Hollinsgsworth, Leta (Mrs.), Teachers College, Columbia University, New York.

Hughes, W. H., Supervising Principal, Claremont, California.

Inglis, Alexander J., Harvard Graduate School, Cambridge, Massachusetts. Knight, F. B., University of Iowa, Iowa City, Iowa.

Koos, L. V., University of Minnesota, Minneapolis, Minnesota. Miller, W. S., University of Minnesota, Minneapolis, Minnesota. Myers, Garry C., Cleveland School of Education, Cleveland, Ohio. Neale, M. A., University of Minnesota, Minneapolis, Minnesota. Peterson, Joseph, Peabody College, Nashville, Tennessee. Pressey, L. C. (Mrs.), Ohio State University, Columbus, Ohio. Pressey, S. L., Ohio State University, Columbus, Ohio.

Stenquist, J. L., Bureau of Reference, Research, and Statistics, Public Schools, New York City.

Swift, F. H., University of Minnesota, Minneapolis, Minnesota. Strayer, G. D., Teachers College, Columbia University, New York City. Stevenson, P. R., Ohio State University, Columbus, Ohio.

Toops, H. A., Teachers College, Columbia University, New York City. Williams, J. Harold, Bureau of Juvenile Research, Whittier, California. Witham, E. C., Superintendent of Schools, Putnam, Connecticut. Washburne, C. W., Superintendent of Schools, Winnetka, Illinois. 